\title{
The Analysis Of Bahasa Rupa And Digital Storytelling In Raya And The Last Dragon Movie
}

\author{
Citra Kemala Putri ${ }^{1}$
}

\author{
${ }^{1}$ Universitas Informatika dan Bisnis Indonesia \\ *Email: citrakemala@unibi.ac.id
}

\begin{abstract}
Each ethnic has its own word-language, the interesting part of word-language is how the same object is called by different names in different languages and in different places. Each image also has its esthetic aspect which is the symbolic aspect, and each ethnic has its own way to draw the same object. Tabrani Primadi called this as Bahasa Rupa aspect. Bahasa Rupa is a knowledge that can help us to interpret various images that present without text. Tabrani Primadi divides this Bahasa Rupa into two systems. First, Bahasa Rupa system called NPM (NaturalistPerspective-Momentopname) is known as modern Bahasa Rupa. Second, another Bahasa Rupa system called STP (Space-Time-Plane) is known as traditional Bahasa Rupa. At this time when technological progress has been developing very rapidly, we see many types of images, not just still images, but also moving images such as animated movies. One of them is Raya And The Last Dragon produced by Walt Disney Pictures. The movie is set in the fictional realm of Kumandra which the visual details make the set look similar to South-East Asia. The movie contained both STP and NPM systems, which make this movie interesting to be analyzed. This research uses qualitative methods and uses the Bahasa Rupa and Digital Storytelling Theory in analyzing the various visuals and several aspects of this movie. The result of the research describes that although this movie is dominated by NPM system, but it proves that the use of STP system is not limited to create traditional images only. With the help of digital storytelling and digital editing, visuals of an animated movie can be combined with the NPM Bahasa Rupa that could strengthen the delivery of a story through visuals.
\end{abstract}

Keywords: Bahasa Rupa, STP, NPM, animated movie, digital storytelling.

\section{INTRODUCTION}

According to Primadi Tabrani, in interpreting images that are primitive or images that are present without text, we can utilize the method of Bahasa Rupa. Apart from primitive reliefs, in everyday life we often find examples of images that contain Bahasa Rupa systems, but because we are not used to digesting images from the Bahasa Rupa's perspective, we become less thorough in assessing an image [1]. Tabrani then divides Bahasa Rupa systems into two, first, modern Bahasa Rupa from the West or what he called NPM (Naturalist-Perspective-Moment opname) and another system that he called STP (Space-Time-Plane). Bahasa Rupa can be divided into 4: (1) Image Content (Wimba); (2) Image Way (Cara Wimba); (3) Inner Grammar (Tata Ungkapan Dalam) ; and (4) Outer Grammar (Tata Ungkapan Luar). In this research, the author will only analyze Wimba and Cara Wimba of the movie.

One of the modern animated movies that contain both NPM and STP Bahasa Rupa systems is Raya And The Last Dragon. It is a 2021 American animated fantasy adventure action movie, produced by Walt Disney Pictures and Walt Disney Animation Studios, and distributed by Walt Disney Studios Motion Pictures. This movie is approximately 1 hour 47 minutes long. Raya and The Last Dragon tells the story of Raya's adventures as she tries to reunite 5 kingdoms to again become Kumandra. Each kingdom is said to have a different culture, which is inspired by various places in Southeast Asia.The kingdoms were named Heart, Fang, Talon, Spine and Tail. Raya herself comes from Heart Kingdom. 


\section{METHODOLOGY}

The research is focused on discussing the movie's assets of Raya And The Last Dragon, specifically in the first 2 minutes of the movie. This movie is chosen because it is one of the few movies that combines modern and traditional Bahasa Rupa. In the beginning, the author break movie's assets into 3, include: (1) Narrative; (2) Visual; and (3) Audio. These assets build on each other to strengthen the seven elements of Digital Storytelling include: (1) The Point of view, (2) A Dramatic Questions; (3) Emotional Content; (4) The Gift of Your Voice; (5) The Power of Soundtrack; (6) Economy; (7) Pacing. The Visual Assets that contain in the movie include both NPM (modern) and STP (traditional) Bahasa Rupa. There are several experts of Visual Language and Digital Storytelling. In this research the author refers to Primadi Tabrani's Bahasa Rupa and Lambert's Elements of Digital Storytelling. Qualitative methods can be more useful for analyzing the correlation between Digital Storytelling and Bahasa Rupa in Raya And The Last Dragon movie. It is descriptive and tends to use analysis, the subject's perspective is highlighted in this study. The data presented in this research is available from various sources of literature.

\section{RESULT AND DISCUSSION}

In this session, the author will describe the literature review and research object's data. Afterwards, the author describes the results of the analysis based on the theory of Digital Storytelling and Bahasa Rupa, both NPM and STP.

\subsection{The Characteristics of Bahasa Rupa Systems NPM and STP}

Disney movies generally use NPM throughout the movie, but although in small portions, this movie uses STP in some of its scenes. Bahasa Rupa has 4 elements, include: (1) Image Content (Wimba); (2) Image Way (Cara Wimba); (3) Inner Grammar (Tata Ungkapan Dalam) ; and (4) Outer Grammar (Tata Ungkapan Luar).

As we know that each ethnic has its own wordlanguage, the interesting part of word-language is how the same object is called by different names in different languages and in different places. Each image has its aesthetic aspect that Primadi calls the Bahasa Rupa aspect. In the representative descriptive picture of Bahasa Rupa, each ethnic group can create images of the same object that "represent" the object descriptively. Incredibly, the other ethnic group is usually able to recognize that same object. So the interesting part about Bahasa Rupa is not the Image Content (Wimba), but the way to draw it, Image Way (Cara Wimba) for one image, Inner Grammar (Tata Ungkapan Dalam) for composing the image and Outer Grammar (Tata Ungkapan Luar) to create a serial of pictures "tells" a story beyond its content [1]. In this research, the author will only analyze Wimba and Cara Wimba of the movie.

STP (Space-Time-Plane) system is a natural gift of children from 2 to 11-13 years, so adults should not replace their natural Bahasa Rupa with an "adult" western NPM system. It is more prudent to equip children with the natural STP system along with the NPM system, but it can be done only when the growth of the child is ready enough for it. With that way every child can develop his unique nuance of combining the both systems, since the both systems are required not only for the past but also for the future. The ability to understand the STP system may be a necessary partner of NPM system. With the combination of the both systems, we can open up the world of Einstein Relativity theory in visual art [1].

The NPM system (Naturalist-Perspective-Moment opname) depends on the ability of our eyes in order to capture the scenes: the image is shot from one angle, one distance, at one time. The scene becomes a still picture that froze an instance, framed and it only explains what the objects are in the picture. The NPM system is more relevant with Newton's classical physics space, two dimensions consist of only length and width, while three dimensions consist of lengthwidth-height, without time dimension, but produce a strong illusion of space [1].

The characteristics of the STP (Space-Time-Plane) system are: an image shot from multiple angles, multiple distances and multiple times. The Image becomes a sequence because it has the time dimensions and can consist of several scenes. The objects then become images that are not frozen and framed, but move in space and time. So a picture does not only explains of what objects are drawn, but also tells a story and an expression into a visual language, just like word language. The size of an object has nothing to do with distance, but rather has something to do with the importance of the object in the story. This system is more relevant to Einstein's modern physics (the theory of relativity) which states that space and time are inseparable. Some of the other characteristics of the STP system include: whole body type of shot, so each object is generally drawn from head to toe. Thus it can be concluded that STP tells a story more with gestures, while NPM tells stories 
through facial expressions. An object is drawn by highlighting its distinctive characteristics so that it is easily recognizable. When an important event is narrated, an 'x-ray' or invisibility method is used. There is a way of drawing 'space', so the object is depicted upside down, that means there is something going around, each object can be shifted in whole or in part until all parts are visible and can be told to each other. Both of these Bahasa Rupa systems can be called universal system, but even so, each ethnic group has a different way to describe it [1].

The development of science and technology then brings up photos, movies and television where the picture back should have the ability to tell a story. This is because images have a very important role as a communication medium. Approximately $80 \%$ of the information comes through the senses of the eyes. Therefore, the study of the storytelling aspect of an image into Bahasa Rupa is necessary to be learned [1]. In this study, the author analyze Bahasa Rupa and its correlation with Digital Storytelling of Raya and The Last Dragon movie, specifically the first 2 minutes scenes of the movie.

\subsection{Elements of Digital Storytelling}

A method that could be used to improve children's verbal intelligence is through storytelling methods. The story basically has the structure of a complete word and language. This includes several systems of language rules, such as phonological (system of sound), morphology (rules for combining minimal units of meaning), syntax (rules to compose sentences), semantics (meaning systems), and pragmatic (rules of usage in a social setting). It is expected that using this method for children could help them recognize the words or add their vocabulary [2]. The different things between storytelling and digital storytelling are the practice of combining narrative with digital content, such as images, sound, and video, with the addition of a strong emotional component [3].

Digital storytelling according to Alexa Wheeler is seen as a modern expression of the art of storytelling. The stories that were adapted in a variety of developing media, either orally or on the computer screen. Wheeler also stressed that the screen has been evolved into a variety of devices, portable and mobile. The modern expression includes multimedia, sound, music, still or moving images (video, animation, simulation). According to Wheeler digital storytelling affects the development of literacy and knowledge of the visual media [2].
According to Lambert (2006) there are seven elements of digital storytelling include: (1) the point of view, it can be achieved by understanding the main point of the story and what the author's perspective is; (2) a dramatic question, a key question that keeps the audience's attention until the story is done, because this question will be answered at the end of story; (3) emotional content, serious issues that come alive and powerful. So the audiences have a deeper connection between the story and them; (4) the gift of your voice, since digital storytelling has an audio element, the voice of yours can be used as a way to personalize the story to help the audiences understand the context; (5) the power of the soundtrack, still in audio context, the soundtrack which can be either sound or music can support and enhance the storyline; (6) economy, by using effective content, will be delivered directly so that the story is not overloaded; And the last, (7) Pacing, is the ability to regulate the rhythm of the story and can control how slowly or quickly it progresses [4].

\subsection{Correlation Between Digital Storytelling and Visual Language in Raya And The Last Dragon movie}

Based on the preliminary findings the author found that Raya and The Last Dragon has some assets in it, include: (1) narrative; (2) visual assets contained along the movie, and the last; (3) audio (music, voice and sound). One of the assets that can be developed further is the visual assets. Disney films generally use the visual language NPM throughout the movie, but although in small portions, this film uses STP in some of its scenes. These assets build on each other to strengthen the seven elements of Digital Storytelling.

The research utilized the Digital Storytelling approach. This approach is used by considering the value and power of storytelling that is universal across cultures and disciplines, that could be valid from time to time. There is evidence that preliterate cultures (societies that still cannot read the letters) relied on storytelling to educate the community, so they relied on the ability to the retelling accurately. In the 20th century, telling stories is a form of entertainment that became experiences that are embedded in the earliest of our memories [3]. So with this approach, the various systems of rules that contained in the storytelling can be collaborated with digital contents, not only keeping the authentic aspects but also delivering the message in a more interesting way.

If pictures, paintings and photographs are defined as still images, then images that appear on movie and TV are defined as motion images. Movie and TV use 
the concept of NPM in every frame [1]. So even though some scenes of Raya And The Last Dragon contains STP system, it is still interpreted as an animated movie which contains a combination of two Bahasa Rupa systems, because the movie uses a screen as its' frame. The interesting part about this movie is the use of STP Bahasa Rupa in the first 2 minutes of the movie. This part narrated by Raya tells a flashback story of 500 years ago, where at first humans and dragons coexisted in the land of Kumandra. But there is an evil force (Druun) that attacked the land, causing the dragons to sacrifice themselves for humans. These dragons gather the last of their strength into the dragon's gem, and leave it to the last dragon (Sisu). After Druun is gone, those humans actually fight for having the dragon's gem, thus resulting in Kumandra disintegrated into five kingdoms, Heart, Fang, Talon, Spine and Tail. This part plays an important role as the element Point of View, which presents the main theme of the story.

After those 2 minutes, the scenes were dominated by NPM system. It tells the story of 500 years later, when the evil power again disturbs after the kingdoms broke the dragon's gem, their fate depends on Raya as dragon's gem guardian. Together with his loyal friend, Tuk Tuk, and several friends he met along the way, they fought with the last dragon, Sisu, to reunite the land of Kumandra. At the beginning of this part, Dramatic Questions are poised to be answered as the story flows, including "where is Sisu?", "Will Kumandra be reunited?". In this part, Emotional Content also begins to be built, which is very visible in the relationship between Raya and her father. Raya's adventure in looking for Sisu is not only to bring Kumandra back, but also to return her father after the Druun turns everyone he touches into stone, including Raya's father. Various things that Raya went through also made her have trust issues which made her often argue with Sisu. This movie has great Pacing, slow at first to build a connection with the audience. But the plot is getting faster until it reaches the end of the story.

Raya and the Last Dragon presents a variety of unique elements inspired by the natural beauty and rich culture of Southeast Asia, including Indonesia. Several talents from Indonesia were actively involved in making this movie. Starting with the artist Griselda Sastrawinata, she was again involved in making this movie as a visual development artist with Luis Metal as a story artist. Several cultural activist figures were also involved in this movie, such as Dewa Berata and Emiko Susilo. Both of them are part of the consulting team, especially in terms of Indonesian culture, traditional dances and ceremonies, and gamelan music. This diversity can be seen in motifs, colors, architecture, foods, to values, habits and customs those are very close to people's daily lives in Southeast Asia. Raya wears a hat that looks like Salakot - name for traditional headgear in Philippines. Raya's loyal friend, which is also the means of transportation, is called Tuk Tuk - the name for the rickshaw which is a popular mode of transportation in the Southeast Asia region. And its fighting techniques are inspired by Silat - a traditional martial art commonly practiced in Malaysia and Indonesia.

The following is the author's analysis towards the visual assets in the Raya and The Last Dragon movie according to Bahasa Rupa and Digital Storytelling approaches.

\subsubsection{Isi Wimba (Image Content) Raya and The Last Dragon}

Isi Wimba refers to the objects that are drawn on the movie [1]. Raya And The Last Dragon is a movie which has many visual objects. In addition to several main objects in the form of human figures, there are also supporting objects such as dragons, animals, as well as visual assets that support the setting of place and time.

\subsubsection{Cara Wimba (Image Way) Raya And The Last Dragon}

Cara Wimba is a way of drawing objects contained in the movie [1]. Cara Wimba is grouped based on Capture Size, Capture Angle, Scale, Depiction and View Mode. All of these groups of Cara Wimba seem used throughout the movie, but in this session we will discuss specifically of Cara Wimba in the scenes of the first 2 minutes of the movie.

\subsubsection{Cara Wimba 1: Type of Shot}

Type of Shot is a capture technique in order to determine how large the contents of Isi Wimba are depicted in an image field and it can be explained in two types of Type of Shot, namely the modern one that uses a frame and the traditional frame-free method [1]. In this movie, the Type of Shot used is a modern way of using frames. This is absolute considering all movies are always watched through screen media which has a limited area.

There are 11 types of modern method Type of Shot, including extra close up, very close up, big close up, close up, medium close up, midshot, medium shot, medium long shot, long shot, very long shot, and extra long shot [1]. These 11 types of modern Type of Shot 
are alternately used throughout the movie, interspersed with a number of traditional Type of Shot. The Type of Shots those are often used in this movie are close up and medium close up. This is the difference between Western visual language (NPM) and traditional Bahasa Rupa (STP) which is often seen in comics, advertisements and movies. The use of close-ups is due to Western artists assessing that facial expressions play a very important role in the story framework [1]. It is also seen in many scenes in Raya And The Last Dragon movie. Close ups are widely used to display various character expressions to strengthen the storyline.

Meanwhile, the tradition ways that appear include:

a. Some are enlarged (how to depict Wimba or parts of Wimba larger than other Wimba) [1], on Figure 1 Humans and Dragons were depicted larger than its environment.

b. Some are reduced (how to depict Wimba or the presence of parts of wimba made smaller than other wimba) [1], for example on Figure 1, mountains and waterfalls were depicted smaller than humans and dragons.

c. Depicted whole body [1], in some scenes, many figures are drawn from head to toe. As said before, if the modern way uses expression to strengthen the story, then tradition uses gestures to explore the story, for example on Figure 1 humas were depicted whole body.

As said before, for STP system, size has nothing to do with distance, but rather has something to do with the important part of the story. The relation between Humans and Dragons were the highlight of the story, so they were depicted larger in many scenes of the first 2 minutes of the movie. By combining both types of NPM and STP Type of Shot, it can strengthen three elements of Digital Storytelling, include: (1) Emotional Content; (2) Economy and; (3) Soundtrack. The use of expression (NPM) and gesture (STP) plus the right sound effect (or soundtrack) help convey messages of the story, without adding a lot of dialogue, make the scenes emotionally compelling. There is no doubt that Disney is the expert in combining soundtracks and voice actors to conveying emotions of the movie.

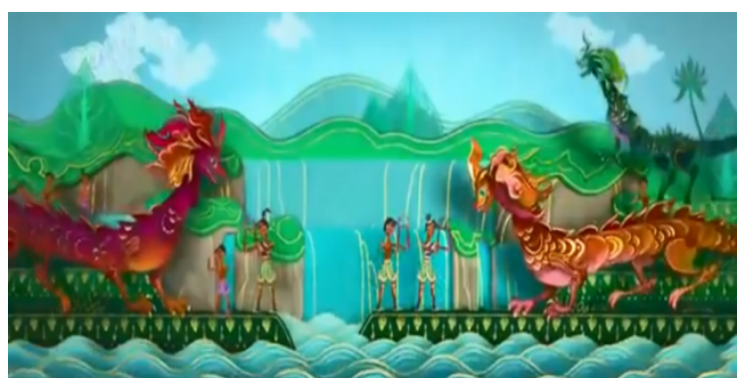

Figure 1 Human and Dragons coexisted in Kumandra

\subsubsection{Cara Wimba 2: Camera Angle}

Camera Angle is the way of taking pictures or the way of depicting a wimba, so that we can see the object from a certain point of view [1]. Modern camera angles that often used in this film include a normal angle (a way of depicting an image that looks natural at eye level), and a bird's-eye view angle (a way of depicting an image so that the object appears from above at a distance, so that the object and its environment can be seen from above (Figure 2). Meanwhile, the traditional camera angle that are being used are multiple angles (the way of depicting an image as if it appears from multiple directions, distances and times). In Figure1, dragons and humans are depicted facing sideways, but their eyes are facing forward.

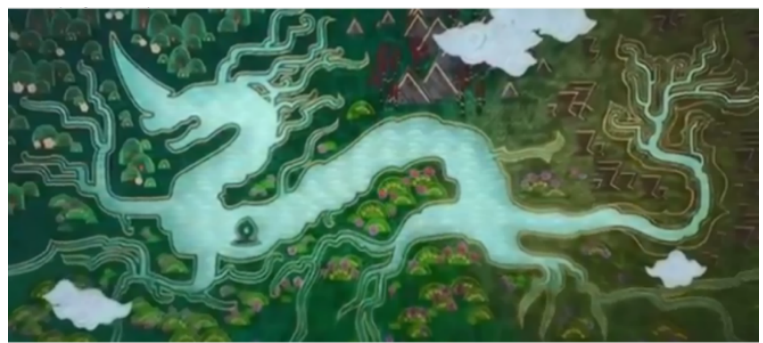

Figure 2 Kumandra from above.

\subsubsection{Cara Wimba 3: Scale}

Scale is the comparison between the height of the object drawn and the actual height of the object [1]. This movie uses several modern scales, including: smaller than the original, the same as the original and larger than the original. While the tradition scale used is the giant size scale, the image is far away as large as a giant even though the original object has normal size. The size of an object has nothing to do with distance, but has something to do with the importance 
of the object in the story. The bigger the object, the more important its role in the story is. In Figure 3, Sisu is gathering strength into the dragon's gem, to defeat Druun. Sisu is visualized larger than her actual size, as seen from the comparison of Kumandra below. This scene is one of the most important scenes of the movie.

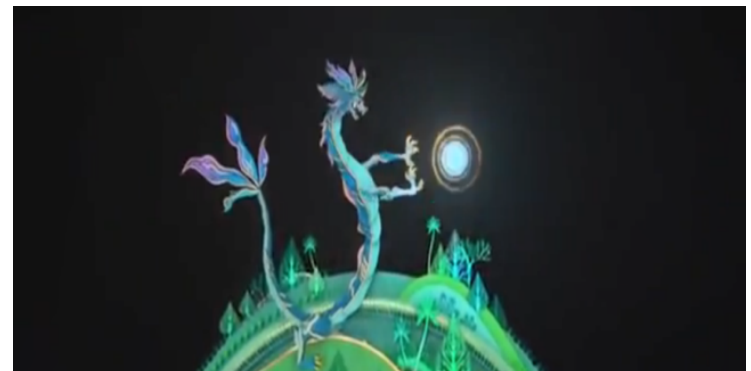

Figure 3 Sisu is gathering strength into the dragon's gem.

\subsubsection{Cara Wimba 4: Depiction}

Depiction is a way of using art elements such as lines, colors, etc. in order to describe an object [1]. Modern methods used in this film include:

a.Naturalist, the way of depicting inanimate and animate objects as they are seen by the eye.

b.Perspective, the way of depicting image objects that are located either in the foreground, middle, or back, thus creating the illusion of space in the image with one or two vanishing points.

c.Simplification, the way of depicting an object or human by simplifying the parts of the object, so that it seems to be drawn in a naturalist way but simplified. The degree of simplification can be various.

d.Expressive, the way of depicting objects or humans that emphasize the expression of feelings, ambience or motion.

e.Distortion, the way of depicting objects or people so that it appears that parts of the object are changed so that they are not naturalistic. Can be extended, shortened, enlarged, reduced, etc.

f.Decorative, the way of depicting an object which is arranged in such a way on the drawing space, so that it forms a composition that is eye pleasing.

g.Outline, the way of depicting an object by using lines around the object.

h.Volume, the way of depicting an object by giving its volume so that each wimba and its parts appear to be three-dimensional in the image.
i.Silhouette, the way of depicting object with using colors evenly throughout the image so that the image looks flat.

j.Color, the way of depicting an impression of an object by using various colors.

k.Field, the way of depiction so that each image object, its parts, and backgrounds appear flat, which creates a strong two dimensional impression

1.Momentopname, The way of describing events that take place at 'one' moment from 'one' place and from 'one' direction, also called still picture [1].

Points c, e, g, i, k are seen dominantly in the first 2 minutes of this movie, while other points are seen in the scenes after that. Beside the modern method mentioned above, this movie also uses traditional ways of depicting a picture, including Events, which is the way of depicting wimba which involves changing time spells and various angles of appearance. In Figure 5. The scene is like layers. The back layer shows the first event, the next events are sequential according to the layer position. The front layer is the most recent.

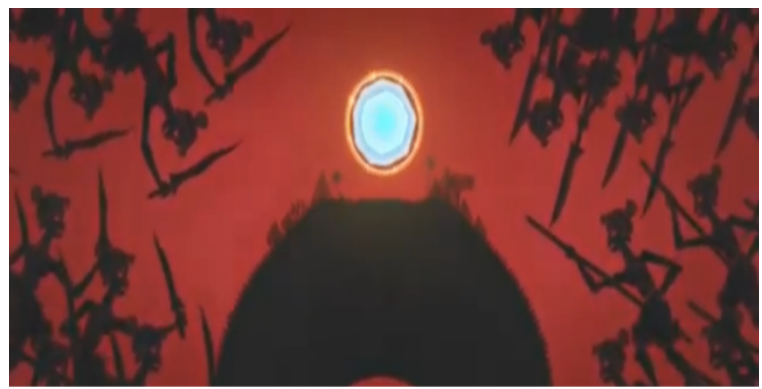

Figure 4 The Kingdoms are fighting over the dragon's gem.

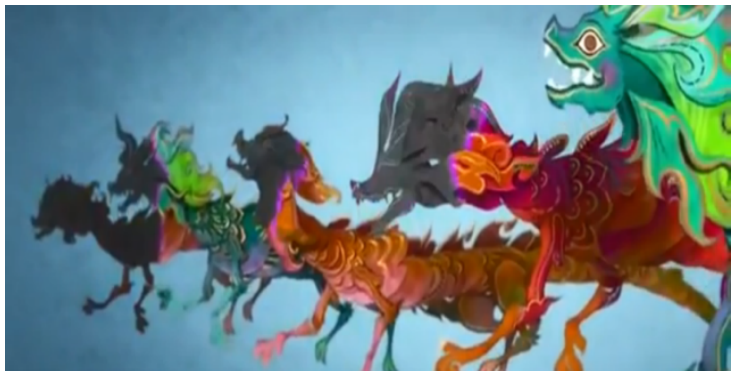

Figure 5 The dragons are turning into stone. 


\subsubsection{Cara Wimba 5: View Mode}

View Mode is the way a viewer enjoys the images so that he can capture the content of the image, for that the viewer must see the image in various ways, according to the guidelines that have been created in such a way [1]. This view is intended especially for images that are static. However, to enjoy this movie, there are several modern ways that can be used, including through a normal view angle which is the way to look at an image because the position of the image made is even to the average human view, or the way the depiction looks natural with normal view direction. So without even looking away, the image can be seen in its entirety.

Meanwhile, the traditional view mode that appears in several scenes is "face to face" (jagongan), refers to direction of viewing determined by the position of the wimba which are depicted facing each other, even though the position of the characters in this movie has no meaning or arranged randomly (Figure 1). Another traditional view mode is "middle to the edge", the important wimba is in the middle, while the supporting wimba is on the edge, so that the viewer will see sequentially from the middle to the edge (Figure 4).

\section{CONCLUSIONS}

According to Primadi, traditional Bahasa Rupa is not only valid in the presence of traditional art, but also in the future. So it can provide a chance for us to get step ahead, than just go along with using Western Bahasa Rupa [1]. Any movie and its STP could "jump" from a conventional media to a digital media by utilizing the theory of science and novelty of technology so that the original purpose of the epic story which is to give moral teaching can be achieved and at the same time enrich and release the saturation of traditional arts.

Raya And The Last Dragon animated movie proves that the combination of NPM system and STP system is very possible. Tradition Bahasa Rupa is not always used to produce something ancient, old and not modern. On the other hand, modern Bahasa Rupa is not always used to tell a modern story. Various technological findings such as digital editing as well as supporting theories such as digital storytelling also support the successful combination of both NPM and STP in a movie. The result of the combination of Bahasa Rupa and Digital Storytelling produces beautiful stories, visual presentations, audio, which are very rich to be digested by our senses, translated by our imagination, and touch our emotional side.

\section{REFERENCES}

[1] Tabrani, Primadi, Bahasa Rupa, Kelir, Bandung, 2012.

[2] Remi, Citra Melati, Perancangan aplikasi (APP) Buku Digital Sri Pohaci Untuk Anak PraSekolah: Pengenalan Sembilan Tanaman Pangan Pokok. Thesis Program Studi Magister Desain Game dan Digital Media, Fakultas Seni Rupa dan Desain, ITB, 2013.

[3] McGee, Patricia, The Instructional Value of Storytelling: Higher Education, Professional, And Adult Learning Settings. Routleddge, New York, 2015.

[4] Tenh H K, Norshuhada S, Harryizman bH. Core Elements of Digital Storytelling from Experts' Perspective. Paper presented at Knowledge Management International Conference (KMICe); 2012 July 4-6, Johor Bahru, Malaysia. p. 397-402

[5] Sinopsis Raya And The Last Dragon, Perjuangan Mencari Naga, https://www.cnnindonesia.com/hiburan/202103 03120519-220-613126/sinopsis-raya-and-thelast-dragon-perjuangan-mencari-naga accessed on July 5, 2021.

[6] Tan, Yvette, 'Raya And The Last Dragon': Cerita Disney pertama yang tampilkan pahlawan perempuan dari Asia Tenggara. https://www.bbc.com/indonesia/majalah56310579 accessed on July 5. 2021. 